\title{
O Perfil do "Emprego" em Saúde no Brasil
}

* Sabado Nicolau Girardi

\section{APRESENTAÇÃO}

Os estudos sobre a força de trabalho em saúde, que buscam captar o processo de sua formação e uso, em sua totalidade, integrando seus elementos sócio-demográficos, políticoideológicos e econômicos em um único esforço explicativo, estão praticamente se iniciando no Brasil.

Vale apontar para os trabalhos pioneiros de Maria Cecilia Ferro Donnangelo, sobre o mercado de trabalho médico e a sociedade, em meados da década de 70 e posteriormente os de Roberto Passos Nogueira intentando demarcar a dinâmica da relação capital trabalho nos serviços de saúde.* Mas recentemente, a partir de 1982, o Núcleo de Recursos Humanos da Escola Nacional de Saúde Pública, empreendeu um esforço de pesquisa em que se buscava dar um tratamento simultâneo dos aspectos relativos à evolução da oferta e da demanda por força de trabalho em saúde na década de 70. Nestes estudos adotava-se a concepção de que "oferta e demanda constituem duas faces de uma mesma moeda mas os impactos de uma sobre a outra não ocorrem de imediato, . . . (Existindo) sempre uma defasagem temporal entre os impactos que cada uma delas exerce sobre a outra. Esta defasagem é que possibilita entender determinados "desajustes", refletidos, no caso da força de trabalho, em desemprego ou subemprego..."3

Pretende-se tão somente, nos limites deste trabalho, traçar um quadro panorâmico de "emprego" em saúde, identificando alguns de seus aspectos quali-quantitativos mais evidentes sem a intenção de detalhar a questão do emprego sob suas determinaçöes mais abrangentes.

Cumpre ressaltar que as principais tendências que caracterizaram a inserção da força de trabalho no setor saúde,na década de 70 , bem como as perspectivas de sua evolução,já foram apontadas e analisadas em seus aspectos mais importantes, em outros trabalhos, especialmente os desenvolvidos pela ENSP/OPAS, sob a coordenação de R. Nogueira e A. Medi$\mathrm{ci}^{4}, 5$

Os dados utilizados neste artigo fazem parte do acervo da Pesquisa "Dinâmica do Emprego em Saúde no Brasil, 1976/84", em desenvolvimento pela Escola Nacional de Saúde Pública/Universidade Federal de Minas Gerais, com supervisão e apoio de IBGE, do Programa de Infra-Estrutura de Serviços de Saúde da OPAS. Nesse sentido constitui-se em resultado parcial de esforço coletivo de pesquisa** Os erros e insuficiências de análise e interpretação, entretanto, são de responsabilidade única e exclusiva do autor.
* Médico Sanitarista, Especialista em Medicina Social, Supervisor Técnico da SECRETARIA DE ESTADO DA SAÚDE/MG

* - Referimo-me muito especialmente d "Medicina e Sociedade: 0 Médico e o seu mercado de trabatho", São Paulo, Livraria Pioneira, 1975 de Maria Cecllia Ferro Donnangelo e d "Capital e trabalho nos serviços de Saúde" de Roberto Passos Nogueira, mimeo.

* Agradecimentos especiais a Roberto Passos Nogueira, pela dedica. ção com que tem nos contemplado, 
orientando nossos trabalhos $e$ discussöes sobre o tema e d Maria Helena Machado, que juntamente com o autor participam do esforço de Pesquisa "Dinâmica do Emprego em Saude no Brasil, 76/84".

Da mesma forma agradeço a Marcelo Torres T. Leite - NES. CON/UFMG, pela colaboração na discussão e revisão do trabalho.

\section{INTRODUÇĀO: ASPECTOS CONCEITUAIS}

A Força de Trabalho em Sadde, pode ser definida como a parcela da população que, tendo alguma formaçăo, preparo, ou um conjunto de determinadas destrezas nas profissóes da saúde, encontra-se ocupada ou à procura de ocupação em atividades do setor.

Como qualquer outro tipo de força-de-trabalho, pode ser estudada sob dois aspectos: o da oferta e o da demanda ${ }^{5}$. A oferta refere-se à totalidade das pessoas que se encontram à procura de oportunidades de trabalho, seja pelo fato de terem ingressado recentemente no mercado (por exemplo os jovens e recém-formados, seja por que se encontram em trânsito de um emprego ou ocupação para outro, seja porque tiveram suas formas anteriores de exercício profissional, parcial ou totalmente destruídas, pelo avanço do movimento de "institucionalização" do trabalho em saúde, se vêem obrigados a vender uma parte ou a totalidade de suas horas de trabalho no mercado. A demanda, por sua vez, "refere-se à totalidade dos postos de trabalho ocupados ou vacantes, proporcionados por empresas ou instituições do setor" 5 .

Para se ter uma melhor compreensão da dinâmica da oferta de Força de Trabalho em Saúde, podemos recortá-la em dois segmentos esquemáticos: no primeiro deles agrupamos as profissões de saúde formalmente reconhecidas pelo sistema de ensino. Neste caso, tanto o volume, como a estrutura da oferta serão basicamente regulados pelas "potencialidades" do sistema formador, pressionados de um lado por demandas sociais, demográficas e político-ideológicas e por outro pelas necessidades da estrutura produtiva. No segundo segmento podemos agrupar o imenso contingente de pessoas que ingressam no setor, sem qualquer nível de qualificação ou preparo prévio. Neste caso, tanto o volume como a estrutura da oferta, podem variar em limites bastante amplos, de acordo com a performance conjuntural e a capacidade de geração de empregos ou ocupações dos diversos ramos de atividade e setores da economia, num dado momento histórico.

Assim, também, o volume e a estrutura da demanda, por força de trabalho em saúde, refletem as formas concretas de organização da prestação de assistência à saúde das pessoas.

Sob o impacto das alterações da estrutura do processo de trabalho em saúde e das mudanças tecnológicas, verificam-se modificações qualitativas e quantitativas na estrutura da demanda de força de trabalho, determinadas pela nova composição da divisão técnica do trabalho. Ademais, a densidade e o direcionamento que assumem as Políticas Sociais em cada conjuntura histórica farão variar sobremaneira a demanda por Força de Trabalho em Saúde.

Dessa forma, o processo de produção e reprodução da Força de Trabalho em Saúde, sua oferta e sua demanda, "não resultam apenas da dinâmica populacional, como a teoria convencional faz crer, mas do movimento da população entre os diferentes modos de produção" (formas de organização da produção) ${ }^{6,7}$.

Cadernos de Saúde Pública, R.J., 2 (4):423-439 out/dez, 1986 


\section{A EVOLUÇĀO DOS "EMPREGOS” DE SAÚDE: LINHAS GERAIS}

A expansão do emprego em saúde se encontra vinculada ao movimento de "terciarização" das atividades econômicas, verificado no Brasil ao longo das últimas décadas.

Entre 1950 e 1980, o setor terciário teve sua participação aumentada de $26 \%$ para $46,6 \%$ do contingente de pessoas ocupadas no país 4 .

Em 1984, estas cifras já alcançavam os $48,04 \% 1$ e espera-se que atualmente tal contingente já se constitua na maioria absoluta do total de pessoas ocupadas.

Ao mesmo tempo, neste mesmo ano, as "atividades sociais" (serviços de "consumo coletivo"), absorviam 7,5\% do total de pessoas ocupadas e $15,6 \%$ ds ocupadas no setor terciário. Os estabelecimentos de saúde, então respondiam por $24 \%$ das pessoas ocupadas em atividades sociais*.

Assim, estudar a dinâmica do emprego* nos estabelecimentos de saúde, significa apontar para as formas concretas de inserção de cerca de 1.000.000 (um milhão) de postos de trabalho na atual estrutura ocupacional brasileira.

Quanto ao crescimento dos empregos de saúde, pode se verificar que, a despeito das dificuldades enfrentadas pela economia brasileira, a partir de meados da década de 70, com desaceleração do crescimento e declínio nos ritmos de absorção de Força de Trabalho, estes se expandem a taxas vigorosas.

Os dados de que dispomos indicam que entre 1976 e 1980, os empregos típicos* de saúde cresceram, nos estabelecimentos médico-sanitários, a taxas geométricas significativamente maiores que o incremento da PEA. Enquanto a PEA cresceu em $4,1 \%$ ao ano, os empregos de saúde cresceram $8,6 \%$ ao ano. A taxa esperada para o crescimento das oportunidades de emprego, prevista pelo II PND para o conjunto da economia, era de $3,5 \%$ ao ano e já se admitia, inclusive, a impossibilidade de se atingir tal meta ${ }^{2}$.

Mesmo o acirramento da crise econômica nos anos 80 , que acarretou desemprego aberto para vários setores da economia, especialmente os industriais mais dinâmicos, não fez arrefecer os ritmos de crescimento dos empregos de saúde, pelo menos até 1982. Entre 80 e 82, por exemplo, os empregos de saúde cresceram 7,31\% aa.

As razões que poderiam explicar este comportamento peculiar do setor saúde, no que respeita a sua demanda por força de trabalho, devem ser buscadas nas especialidads que marcam as relações entre estes serviços, o estado e a estrutura produtiva, na formação social brasileira.

Em primeiro lugar, poderia se apresentar na raiz deste comportamento o fato de serem os serviços de saúde largamente sustentados pelo estado. Verifica-se, por exemplo, que independentemente da natureza privada ou pública dos estabelecimentos pesquisados, a maioria absoluta dos "empregos" de saúde mostraram-se direta ou indiretamente remunerados Cadernos de Saúde Pública, R.J., 2 (4): 423-439, out/dez, 1986
* Para a melhor delimitação desse fenômeno é interessante apontar para dois fatores. Em primeiro lugar, é importante se ter em conta que, mesmo que se tenha assistido nas duas últimas décadas, ao desenvolvimento de um terciário dinâmico e moderno, este é um setor tradicionalmente pouco capitalizado, se apoiando em uma oferta abundante de força de trabalho desqualificada, mal-remunerada e caracterizada pelo sub-emprego. Em segundo lugar, em razáo das peculiares relaçöes do setor serviços com o restante da estrutura produtiva, o estado aqui se apresentou como um dos principais incentivadores de sua expansão, especialmente no que tange aos serviços de "consumo coletivo" - consultar a este respeito Medici, André César - "Estrutura de Dinâmica da Força de Trabalho Médici no Brasil dos anos 70" - 1984, mimeo; e Oliveira, Francisco de - "A Economia da Dependência Imperfeita" - RJ - Graal-1977.

\section{* Utilizaremos, indistintamente os termos "empregos" e postos de tra- balho, nos limites destes artigos, apesar das diferenças conceituais evidentes.}

* Por razōes metodologicas, optamos por trabalhar apenas com os empregos de categorias profissionais tipicas da saúde, excluindo do portanto de nossa análise os empregos administrativos e de serviços gerais, bem como aquelas categorias não discriminadas e classificadas como "outros" na AMS. Os nossos totais de empregos referem-se portanto a soma dos postos de trabalho das seguintes categorias: nivel superior: médicos, enfermeiros, odontologos, psicólogos, farmacêuticos, nutricionistas, assistentes sociais e sanitaristas - nível médio: Téc. Laboratório, Téc. Operadores de Raios X, Téc. de Enfermagem, Auxiliares de Enfermagem, Téc. de Saneamento e Aux. Saneamento - nível elementar: atendentes, parteiras, visitador sanitário, guarda sanitário. As razōes que nos impeliram a tal procedimento foram as modificaçōes verificadas na AMS em 1978 e 1981, que comprometem extremamente a comparabilidade dos dados no periodo. A partir de 1981 tal problema já não se verifica. 
* Podemos identificar, no perlodo compreendido entre meados da década de 60 e os anos 80, dois momentos distintos, em relação ds Politicas de Recursos Humanos. $O$ primeiro deles, que vai praticamente até 75/76 (II PND), caracterizou-se pelo incentivo à formação maciça de Recursos Humanos em Saúde, especialmente médicos (e destacando as. pectos quantitativos), visando suprir as necessidades emergentes do modelo assistencial que se erigia. $O$ se. gundo momento caracterizou-se pelo reconhecimento e pela critica das distoções quantitativas e qualitativas existentes, apontando a necessidade de redirecionamento da Politica de Recursos Humanos em Saúde de forma a corrigir em médio e longo prazo as distorçôes existentes (ver a este respeito - Notas sobre a Politica Nacional de Recursos Humanos em Saúde - Relatório Pesquisa Rec. Hum. em Saúde no Brasil - ENSP - RJ - 1983 - mimeo).

* Segundo Machado, Francisco A., a logica da eficiência, do ponto de vista do capital, qual seja a de produzir mais com menores cus. tos, foi "o elemento principal, dominante, inalterado e persistente" perseguido ... "em todos os experimentos da chamada medicina simplificada, da atenção primária ou cuidados primários em saúde" in " $A$ Estratégia de conduçâo das AIS, na região metropolitana de Belo Horizonte" - BH, 1984, mimeo.

426 pelo estado. Os "empregos" de saúde mantidos pelos estabelecimentos públicos, portanto remunerados diretamente pelo estado, somavam 51,01\% dos empregos de saúde, em 1982 (Tabela 5). Neste mesmo ano, os "empregos" em estabelecimentos de saúde, conveniados com o INAMPS perfaziam $59,41 \%$ dos "empregos" de saúde. Estima-se, pelos dados de 1980 , que os "empregos" nos estabelecimentos privados, lucrativos ou não, que guardavam algum tipo de convênio com a Previdência Social, portanto indiretamente remunerados pelo estado, chegavam em 1982, perto de $30 \%$ dos "empregos" de Saúde. Dessa forma, os "empregos" de saúde mantidos exclusivamente pela iniciativa privada e remunerados pelos proprios consumidores, individualmente ou através de alguma forma de convênio ou seguro sem intermediação do estado no seu financiamento direto, não deviam alcançar mais que $18 \%$ dos "empregos" existentes em 1982.

Por outro lado, o fato do setor funcionar como uma espécie de "tampão" para demandas sociais reprimidas, agravadas em conseqüência do modelo econômico, deve contribuir também para o crescimento do volume de empregos no setor, especialmente nos momentos de crise econômica, quando a demanda por estes serviços aumenta.

Todavia, entre 82 e 83, verificamos um declínio no crescimento dos empregos de saúde. Sua taxa de incremento se viu reduzida à metade $(3,46 \%)$, comparativamente ao crescimento nos anos anteriores. Este pequeno crescimento observado, se sustentado nos anos subseqüentes, poderia significar, já um prenúncio de crise, com diminuição da capacidade de geração de empregos do setor.

Entretanto, pelos fatores anteriormente apontados, estamos inclinados a pensar que tal fenômeno não deverá se ver sustentado.

\section{A COMPOSÇÃO QUALI-QUANTITATIVA DO “EMPREGO" NOS ESTABELECIMENTOS DE SAÚDE}

As políticas de Recursos Humanos e de Empregos na área de saúde, postas em prática nas duas últimas décadas, mesmo que propugnassem, no plano do discurso, a partir de meados de 70*, a necessidade de adequação da composição de recursos humanos de nível superior, técnico e elementar, resultaram, quer pela ineficácia do sistema formador, no que diz respeito a oferta de pessoal qualificado de nível médio, quer pela lógica da eficiência amplamente incorporada pelos serviços, inclusive os públicos**, em uma situação de predomínio inequívoco, de um lado de profissionais altamente qualificados e especializados, especialmente médicos e de outro de um contingente expressivo de pessoal desqualificado, com destaque para os atendentes, na dinâmica na absorção de força de trabalho no setor.

Tanto é assim, que em 1976, predominavam, na composição interna do emprego nos estabelecimentos de saúde, os postos de trabalho de nível superior e elementar.

Cadיrnos d. Saúde Públıca, R.J., 2 (4):432-439, out/dez, 1986 
Tal situação permanecerá praticamente inalterada, não se observando qualquer movimentação de destaque até 80 , quando os empregos de nível superior ainda representariam $40 \%$ e o nível elementar $41 \%$ dos "empregos" típicos de saúde.

Estes dados podem ser visualizados na Tabela 1.

TABELA 1

DISTRIBUIÇÃO DOS POSTOS DE TRABALHO DE NÍVEL SUPERIOR, MÉDIO E ELEMENTAR* EM TODOS OS ESTABELCIMENTOS DE SAÚDE BRASIL, 1976/1982

\begin{tabular}{|c|c|c|c|c|c|c|c|c|}
\hline \multirow[b]{2}{*}{ ESCOLARIDADE } & \multirow{2}{*}{$\begin{array}{ll}\text { ANO } & 19 \\
\text { ABSOLUTO }\end{array}$} & 976 & \multicolumn{2}{|c|}{1978} & \multicolumn{2}{|c|}{1980} & \multicolumn{2}{|c|}{1982} \\
\hline & & RELATIVO & ABSOLUTO & RELATIVO & ABSOLUTO & RELATIVO & ABSOLUTO & RELATIVO \\
\hline Nivel Superior & 138.687 & 40,05 & 165.378 & 39,53 & 190.950 & 39,61 & 228.228 & 41,11 \\
\hline Nível Médio & 66.597 & 19,23 & 75.905 & 18,15 & 91.564 & 18,99 & 122.376 & 22,05 \\
\hline Nivel Elementar & 141.011 & 40,72 & 177.036 & 42,32 & 199.591 & 41,40 & 204.537 & 36,84 \\
\hline TOTAL & 346.295 & 100,00 & 418.319 & 100,00 & 482.105 . & 100,00 & 555.141 & 100,00 \\
\hline
\end{tabular}

Fonte: AMS/INGE/ENSP - Pesquisa "Dinâmica do Emprego em Saúde no Brasil, 76-84".

* Exclui postos de trabalhos lotados na administração, apoio e serviços gerais e "outros".

Em 1982, entretanto, já de pode observar um aumento na participação relativa das categorias de nível médio, que passam a representar $22,05 \%$ dos empregos, ao mesmo passo que os postos de trabalho de nível elementar experimentam queda percentual de 4 pontos na composição interna do emprego.

Estes números podem indicar um prenúncio de mudanças nas políticas de absorção de força de trabalho pelos estabelecimentos de saúde.

De fato, os dados indicam que o contingente de postos de trabalho de nível médio, apresentam entre 80 e 82 , índices de crescimento geométrico duas vezes maior que o verificado para a totalidade dos empregos (enquanto aqueles cresceram a taxas de $15,61 \%$ ao ano, estes cresceram 7,31\% aa.). Em contrapartida, no mesmo biênio, empregos de nível elementar viram seu crescimento praticamente anulado $(1,23 \%$ aa.).

$\mathrm{Na}$ verdade, e para sermos mais exatos, esta tendência já se anuncia desde o biênio anterior, quando os empregos de nível médio crescem um pouco mais e os de nível elementar algo menos, que o total de empregos.

Quanto às categorias de formação universitária, se observa um comportamento bastante regular e estável relativamente ao seu crescimento e participação.

A Tabela 2, mostra a evolução dos Postos de Trabalho de nivel superior nos estabelecimentos de saude entre 1976 e 1982.

É importante apontar para o crescimento dos empregos de odontólogos e de psicólogos no período $(11,23 \%$ e $22,22 \%$ ao ano, respectivamente). 
TABELA 2

POSTOS DE TRABALHO* DE NÍVEL SUPERIOR EM TODOS

OS ESTABELECIMENTOS DE SAÚDE BRASIL, 1976/1982

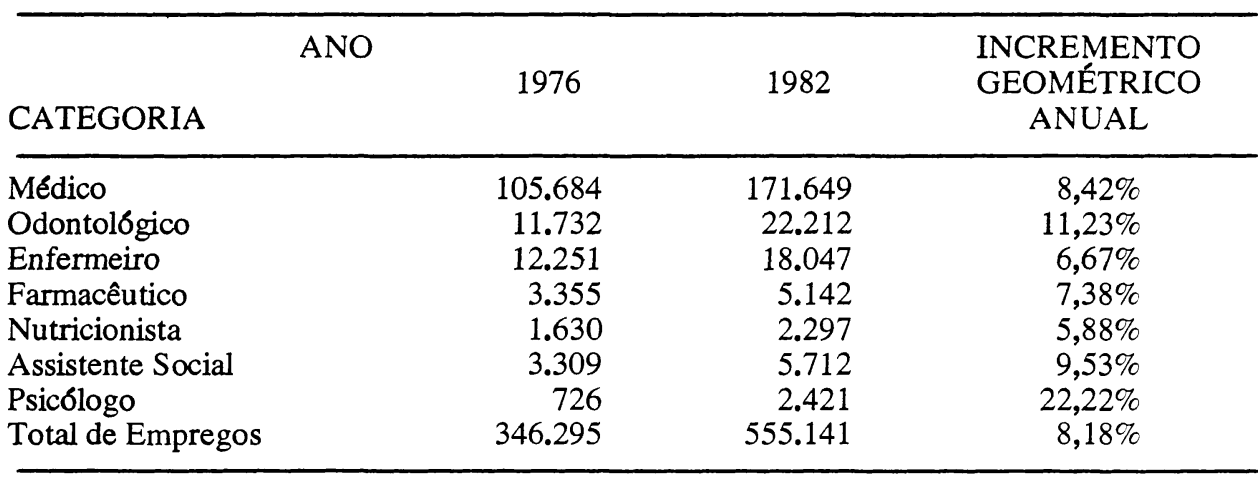

Fonte: AMS-IBGE-ENSP. Pesquisa "Dinâmica do emprego em saúde no Brasil, 76/84" ENSP/UFMG.

* Exclui empregos administrativos, serviços gerais e postos de trabalho não discriminados classificados como "outros".

Ressalte-se, todavia, que a participação ponderal dos empregos de psicólogos no cômputo geral dos empregos de saúde se revela ainda extremamente reduzida. Juntamente com os nutricionistas, se apresentavam em 82 , como as categorias universitárias com menor peso numérico nos serviços $(0,4 \%$ dos empregos para ambas).

Quanto aos odontólogos, o que parece estar havendo é o progressivo assalariamento da categoria, com absorção dessa força de trabalho pelos estabelecimentos de saúde.

Em 1982, tais empregos perfaziam $4 \%$ da demanda global do conjunto dos estabelecimentos médico-sanitários, representando depois dos empregos médicos a categoria de empregos mais numerosos, dentre as universitárias.

Destacam-se ainda, na análise quali-quantitativa da evolução dos empregos de saúde, os postos de trabalhos médicos. Seu crescimento no período, considerando o conjunto dos estabelecimentos, situou-se em $3,42 \%$ ao ano, sendo que estes detinham em 1982, aproximadamente $31 \%$ dos postos de trabalho de saúde.

Em relação aos empregos de enfermeiros, seu crescimento no período situou-se abaixo da média $(6,67 \%$ aa.) e sua ponderação relativa, caiu de $3,54 \%$ para $3,25 \%$ da demanda. Todavia, parece-nos importante ressaltar que, a partir de 79 tais empregos começam a experimentar taxas de crescimento razoavelmente acima do verificado para a totalidade do emprego em saúde.

Em 1983, por exemplo, os empregos de enfermeiros cresceram aproximadamente $3,6 \%$, enquanto os empregos de saúCadernos de Saúde Pública, R.J., 2 (4): 423-439, out/dez, 1986 
de, na sua totalidade, cresciam apenas $3,46 \%$ em relação ao ano anterior. Em relação ao ano de 82, o ano de 83, apresentou significativo decréscimo nas taxas de incremento do emprego em saúde. Os empregos médicos, por exemplo, cresceram $5,1 \%$, os de odontólogos $3,7 \%$, os de técnicos de laboratório $3,9 \%$, os de alxiliar de enfermagem $5,5 \%$ e os de atendentes experimentaram incremento negativo $(-1,0 \%)$ *.

Quanto aos postos de trabalho de nível médio, a Tabela 3 mostra que, com exceção dos técnicos de saneamento, que apresentam crescimento negativo (-10,40\% entre 78 e 82$)$, as demais categorias cresceram em níveis significativamente maiores que os verificados para a totalidade do emprego de · saúde.

Pode-se verificar, que os empregos de técnicos de laboratório cresceram mais que duplamente em relação ao crescimento do conjunto dos empregos ( $18,21 \%$ no período).

Cabe destacar ainda o fato de os empregos de enfermagem de nível médio (técnicos e auxiliares) representam perto de $17 \%$ do conjunto dos empregos de saúde nos estabelecimentos médico sanitários em 82. Os auxiliares de enfermagem, tomados isoladamente, constituem-se, depois dos médicos e dos antecedentes, na terceira categoria de empregos mais representativos, do ponto de vista quantitativo, nos estabelecimentos pesquisados.

A análise da tabela 4 mostra que o crecimento dos empregos de nível elementar viu-se praticamente anulado entre 80 e 82 ( $1,23 \%$ aa.).

Os atendentes, categoria mais importante do grupo, cresceram tão-somente $3,25 \%$ aa. entre 76 e 82 , experimentando inclusive incremento negativo entre 82 e 83 .
* Em números absolutos, os empregos médicos somavam em $1983,180.399$ postos de trabalho nos estabelecimentos, os de enfermeiros 19.592, os de odontologos 23.053 , os de técnicos de laborato. rio 15.242, os de auxiliar de enfermagem 89.899, os de atendentes 177.935. Os empregos "típicos" de saúde somavam 576.127 postos de trabalho quando existiam 883.595 postos de trabalho nos estabelecimentos médico-sanitá. rios. De 1982 para 1983 houve uma perda de 1.883 empregos de atendentes. Os dados são de Roberto Passos Nogueira in "A Dinâmica do Mercado de Trabalho em Saúde no Brasil", publicaçẫo da Organização Pan-Americana de Saúde. GAP Brasilia, 1986.

\section{TABELA 3 \\ POSTOS DE TRABALHO* DE NÍVEL MÉDIO EM TODOS OS ESTABELECIMENTOS DE SAÚDE BRASIL, 1978/1982}

\begin{tabular}{lrrr}
\hline \multicolumn{1}{c}{ ANO } & 1978 & 1982 & $\begin{array}{c}\text { INCREMENTO } \\
\text { GEOMÉTRICO } \\
\text { ANUAL }\end{array}$ \\
CATEGORIA & & & 14.660 \\
\hline Téc. Laboratório & 7.507 & 10.644 & $18,21 \%$ \\
Téc. Raios X & 6.738 & 8.833 & $12,11 \%$ \\
Téc. Enfermagem & 5.868 & 85.210 & $12,30 \%$ \\
Aux. Enfermagem & 53.576 & 612 & $(-110,40 \%)$ \\
Téc. Saneamento & 683 & 2.417 & $12,06 \%$ \\
Aux. Saneamento & 1.533 & 555.141 & $8,18 \%$ \\
Total de Empregos de Saúde & 418.319 & \\
\hline
\end{tabular}

Fonte: AMS-IBGE/ENSP. Pesquisa "Dinâmica do Emprego em Saúde no Brasil, 76/84" - ENSP/UFMG.

* Exclui empregos administrativos, serviços gerais e postos de trabalho não discriminados, classificados como "outros". 
É interessante observar, ao longo do periodo (78/82), um importante declínio na participação relativa dos postos de trabalho de atendentes na composição do emprego de saúde. Em 1978 eles representavam $37,82 \%$ dos postos de trabalho típicos nos estabelecimentos de saúde, sendo a categoria numericamente dominante, ao passo que em 1983 eles já apresentavam menos de $31 \%$ dos postos de trabalho, enquanto os empregos médicos passam a representar a categoria numericamente dominante $(31,31 \%)$.

TABELA 4

POSTOS DE TRABALHO* DE NIVEL ELEMENTAR EM TODOS OS ESTABELECIMENTOS DE SAÚDE

BRASIL, 1978/1982

\begin{tabular}{|c|c|c|c|}
\hline CATEGORIA & 1978 & 1982 & $\begin{array}{c}\text { INCREMENTO } \\
\text { GEOMÉTRICO } \\
\text { ANUAL }\end{array}$ \\
\hline $\begin{array}{l}\text { Atendente } \\
\text { Parteira } \\
\text { Visit. Sanitário } \\
\text { Guarda Sanitário } \\
\text { Total de Empregos } \\
\text { de Saáde }\end{array}$ & $\begin{array}{r}158.227 \\
4.936 \\
3.758 \\
10.115 \\
\\
418.319\end{array}$ & $\begin{array}{r}179.818 \\
5.098 \\
1.072 \\
18.549\end{array}$ & $\begin{array}{c}3,25 \% \\
0,81 \% \\
(-71,15 \%) \\
16,37 \%\end{array}$ \\
\hline
\end{tabular}

Fonte: AMS/IBGE/ENSP. Pesquisa "Dinâmica do Emprego em Saúde no Brasil, 76/84" - ENSP/UFMG.

* Exclui empregos administrativos, servicos gerais e postos de trabalho näo discriminados classificados como "outros".

TABELA 5

DISTRIBUIÇÃO DOS POSTOS DE TRABALHO* NOS ESTABELECIMENTOS DE SAÚDE SEGUNDO A NATUREZA DA ENTIDADE MANTENEDORA BRASIL, 1978/1982

\begin{tabular}{|c|c|c|c|c|c|}
\hline \multirow{2}{*}{$\begin{array}{l}\text { ANO } \\
\text { NATUREZA DO } \\
\text { ESTABELECIMENTO }\end{array}$} & \multicolumn{2}{|c|}{1978} & \multicolumn{2}{|c|}{1982} & \multirow{2}{*}{$\begin{array}{c}\text { TAXA DE } \\
\text { INCREMENTO } \\
\text { GEOMÉTRICO } \\
\text { ANUAL }\end{array}$} \\
\hline & $\begin{array}{c}\text { № } \\
\text { ABSOLUTO }\end{array}$ & $\begin{array}{c}\text { № } \\
\text { RELATIVO }\end{array}$ & $\begin{array}{c}\text { No } \\
\text { ABSOLUTO }\end{array}$ & $\begin{array}{c}\text { № } \\
\text { RELATIVO }\end{array}$ & \\
\hline $\begin{array}{l}\text { Público } \\
\text { Privado } \\
\text { Total de Empregos }\end{array}$ & $\begin{array}{l}195.673 \\
222.646 \\
418.319\end{array}$ & $\begin{array}{r}46,78 \\
53,22 \\
100,00\end{array}$ & $\begin{array}{l}283.188 \\
271.953 \\
555.141\end{array}$ & $\begin{array}{r}51,01 \\
48,99 \\
100,00\end{array}$ & $\begin{array}{l}9,68 \% \\
5,13 \% \\
7,33 \%\end{array}$ \\
\hline
\end{tabular}

Fonte: AMS/IBGE. Pesquisa "Dinamica do Emprego em Saude no Brasil, 76/84" - ENSP/UFMG.

* Exclui as categorias não discriminados e classificadas como "outros", os empregos administrativos e serviços gerais. 
INSERÇĀO INSTITUCIONAL DOS EMPREGOS TÍPICOS DE SAUUDE OU O EMPREGO DE SAÚDE SEGUNDO A NATUREZA DOS ESTABELECIMENTOS

$A$ análise da Tabela 5, evidencia ter ocorrido entre 78 e 82 uma inversão no perfil da distribuição institucional dos empregos típicos de saúde.

Verificou-se que em 1982, os estabelecimentos públicos passaram a deter a maioria absoluta $(51,01 \%)$ dos "empregos".

Pode-se ver que os empregos no setor público, cresceram ao longo do quadriênio, a 9,68\% aa., enquanto que os privados tiveram um crescimento quase que duas vezes menor $(5,13 \%$ ao ano). Excetuando-se os empregos de enfermagem de nível médio (técnico e auxiliares de enfermagem), todas as demais categorias apresentaram crescimento maior nos estabelecimentos públicos que nos privados. Verifica-se inclusive, a nível dos estabelecimentos privados, um déficit absoluto, em 1982, de 6,980 empregos de atendentes, em relação aos empregos existentes em 1980, ao passo que nos estabelecimentos públicos estes empregos cresceram a 6,70\% ao ano.

Verificou-se também que nos estabelecimentos sem internação, os postos de trabalho "típicos" de saúde, cresceram mais vigorosamente que nos públicos com internação, o mesmo acontecendo nos estabelecimentos privados* (Tabela 6).
* A taxa geométrica anual para o crescimento dos postos de trabatho de saude nos estabelecimentos públicos sem internação foi de $11,30 \%$ ao ano, nos estabelecimentos públicos com internação de $8,29 \%$ aa., nos privados sem internação $7,71 \%$ aa., e nos privados com internação de 4,78\% aa. - dados da AMS - IBGE/ENSP.

TABELA 6

DISTRIBUIÇÃO DE POSTOS DE TRABALHO* NOS ESTABELECIMENTOS DE SAÚDE SEGUNDO NATUREZA DA ENTIDADE MANTENEDORA E REGIME DO ESTABELECIMENTO BRASIL, 1978/1982

\begin{tabular}{|c|c|c|c|c|c|c|c|c|c|c|}
\hline \multirow{3}{*}{$\begin{array}{l}\text { REGIME DO } \\
\text { ESTABELECIMENTO } \\
\text { NATLREZA DA } \\
\text { ENTIDADE } \\
\text { MANTENEDORA }\end{array}$} & \multicolumn{4}{|c|}{ COMIILRNACAOO } & \multicolumn{4}{|c|}{ SI:UINTIRNACĀO } & \multicolumn{2}{|c|}{ IOIAL } \\
\hline & \multicolumn{2}{|c|}{$197 x$} & \multicolumn{2}{|c|}{1982} & \multicolumn{2}{|c|}{1978} & \multicolumn{2}{|c|}{1982} & \multirow[t]{2}{*}{$197 x$} & \multirow[t]{2}{*}{1982} \\
\hline & ABSOLLIO & RILAIIIO & ABSOLLTO & RELATIVO & ABSOLLTO & RLLATIVO & ABSOLUTO & RELAIIVO & & \\
\hline Público Municipal & 16.845 & $4,(1,3$ & $21 . \times 72$ & 3,94 & 15.724 & 3,76 & 23.045 &,+ 15 & 32.560 & 44.917 \\
\hline Público Estadual & $+9.4 \times 3$ & $11, \times 3$ & $6 \times .772$ & 12,39 & 32.601 & 7,79 & $51.7 \times 9$ & 9,33 & $82,0 \times 4$ & 120.561 \\
\hline Público Federal & +0.948 & 9,79 & 56,879 & 10,25 & +1.072 & $9,5 x$ & 60.831 & 10,90 & $\times 1.020$ & 117.710 \\
\hline TOTAL PĹBLICO & 107.276 & 25,04 & $1+7.523$ & 26,57 & $\times 8.397$ & 21,13 & 135.665 & $24,+4$ & 105.673 & 283.188 \\
\hline Privado Lucrativo & $90,4(x)$ & $21,(1]$ & $11+.350$ & 20,60 & $13 .+14$ & 3,21 & 24.651 & $+4,4$ & $103 . \times 14$ & 139.007 \\
\hline Privado Nảo Lucrauvo & $106.62 \mathrm{y}$ & $25,+4$ & 123.115 & 22,17 & 12.203 & 2,92 & $9 . \$ 31$ & 1,77 & $11 \times .832$ & 132.946 \\
\hline TOTAL PRIVADO & 107.029 & $+7,10$ & 237.471 & 42,78 & 25.617 & 6,12 & $3+.4 \times 2$ & 6,21 & 222.046 & 271.953 \\
\hline TOTAL DE EMPRE:GOS & $3(14.3015$ & 72,74 & 334.994 & 09,35 & 114.014 & 27,26 & 17() .147 & 30,05 & $+1 \times .319$ & 555.141 \\
\hline
\end{tabular}

FONTE: $A M S-I B G E / E N S P$.

* Exclui as categorias não discrimindas e classificadas como "outros", os empregos administrativos e serviços gerais.

Relativamente aos estabelecimentos públicos verificou-se uma discreta "estadualização" dos postos de trabalho às custas de uma diminuição percentual dos empregos municipais.

Os empregos nos estabelecimentos públicos federais mantiveram sua participação praticamente inal terada. Assim nota-se que são os empregos públicos estaduais, os que apresentaram maiores taxas de crescimento no periodo, seja no segmento sem internação $(12,27 \%$ aa.) seja no segmento com internação (8,58\% ao ano).

Os estabelecimentos privados lucrativos*, no seu conjunto, experimentaram maiores índices de crescimento de emprego Cadernos de Saúde Pública, R.J., 2 (4): 423-439, out/dez, 1986
* A distinção no caso é jurldica e não económica 
que os não-lucrativos. Estes inclusive, no segmento ambulatorial, tiveram seu volume reduzido, em termos absolutos a niveis, inferiores aos de 78. De 1980 para 1981, tais estabelecimentos experimentaram uma perda em números reais, de 5.078 empregos, o que representava $34,23 \%$ dos postos de trabalho ali existentes em 1980.

Há que se ressaltar também o extraordinário impulso verificado no crescimento dos postos de trabalho "típicos" de saúde no segmento "ambulatorial" lucrativo dos estabelecimentos privados (16,43\% ao ano) entre 78 e 82 (Tabela 6).

No que respeita à inserção institucional dos postos de trabalho de saúde, verifica-se que em 1982, os estabelecimentos com internação privados não-lucrativos (beneficentes e filantrópicos) representavam a modalidade de estabelecimento que maior número de postos de trabalho absorvia (22,60\%), seguida de perto pelos estabelecimentos com internação privados lucrativos $(20,60 \%)$. Os estabelecimentos com internação públicos, absorviam então, no seu conjunto $26,57 \%$ e os privados $42,78 \%$ dos postos de então, no seu conjunto $26,57 \%$ e os privados $42,78 \%$ dos postos de trabalho oferecidos pelos estabelecimentos de saúde.

Dentre os "hospitalares" públicos destacavam-se os estaduais que respondiam por 12,39\% dos "empregos".

No seu conjunto, portanto, o segmento com internação dos estabelecimentos de saúde respondiam em 1982 por $69,35 \%$ dos postos de trabalho "típicos" de saúde.

Entre os estabelecimentos sem regime de internação (públicos ou privados) que detinham no mesmo ano, 30,65\% dos empregos "típicos" de saúde, destacavam-se os de natureza pública, responsáveis por $24,44 \%$ da oferta total de "empregos".

Assim, a interpretação destes dados, indicam a possibilidade de estarmos diante de uma dupla tendência: a do aumento relativo da participação do segmento sem internação na absorção de postos de trabalho em saúde e a do aumento da participaçâo do setor público. (ver Tabela 6).

Estamos propensos a pensar, inclusive, que tais tendências deverão se ver reforçadas, nos anos subseqüentes, a partir da criação do CONASP, em fins de 81 e especialmente com a implementação da Ações Integradas de Saúde, que em seu primeiro momento, priorizaram o desenvolvimento da rede ambulatorial e o fortalecimento do setor público prestador de serviços.

\section{A DISTRIBUIÇÃO DOS POSTOS DE TRABALHO TÍPICOS DE SAÚDE PELAS REGIÕES BRASILEIRAS E ALGUNS ESTADOS}

Nas discussões sobre a reforma sanitária no Brasil, transparece como consensual, que um dos obstáculos mais sérios a serem enfrentados com vistas à consecução dos objetivos de universalização da cobertura e garantia da equidade das ações 
de saúde, seja o que diz respeito aos desequilíbrios sócio-regionais na distribuição dos profissionais e empregos de saúde.

As razões que determinaram sua concentração nas regiōes mais urbanizadas e desenvolvidas do país, jâ têm sido suficientemente debatidas e as explicaçōes convergem, de uma maneira geral, para as conseqüências do modelo de desenvolvimento econômico adotado no Brasil, que no limite reproduziu e aprofundou as desigualdades já existentes, concentrando ainda mais a renda nos pólos mais ricos e desenvolvidos no país. Além do que, foi nessas regiões em que se deu uma penetração mais intensa das relações capitalistas na prestação de serviço de saúde.

André Medicim observa que entre 1970 e 1980, verificouse uma relativa melhoria na distribuição regional dos profissionais de saúde. Esta melhoria, contudo, não teve peso suficiente para inverter a tendência apontada.

A Tabela 7, mostra que em 1982 a região Sudeste concentrava 43,55\% dos estabelecimentos médico-sanitários do pais, e nada menos que $55,39 \%$ dos empregos típicos de saúde. No mesmo ano, tal região detinha $43,61 \%$ da população brasileira, o que proporcionava uma relação aproximada de 1 emprego de profissional de saúde para cada 181 habitantes, situação marcadamente privilegiada, comparativamente às demais regiōes do país.

A região Sul, que então detinha $15,61 \%$ da população brasileira, concentrava $18,04 \%$ dos estabelecimentos médico-sanitários e $15,17 \%$ dos empregos de profissionais de saúde. (um emprego para cada 239 habitantes).

As demais regiōes do país, apresentavam maiores desníveis relativamente a este aspecto, com subproporção na relação percentuais de população/concentração de empregos.

TABELA 7

DISTRIBUIÇÃO DE POSTOS DE TRABALHO* E ESTABELECIMENTOS DE SAÚDE POR MICRORREGIÖES FISIOGRÁFICAS BRASILEIRAS BRASIL, 1982

\begin{tabular}{lrrrrrrr}
\hline \multirow{2}{*}{ REGIĀOO } & \multicolumn{2}{c}{ ESTABELECIMENTOS } & \multicolumn{2}{c}{ EMPREGOS } & \multicolumn{2}{c}{ POPULAÇĀO ESTIMADA } & RELAÇĀO \\
& ABSOLUTO & RELATIVO & ABSOLUTO & RELATIVO & ABSOLUTO & RELATIVO \\
& & HABITANTE \\
\hline Brasil & 23.801 & 100,00 & 550.031 & 100,00 & 126.806 & 100,00 & $1 / 231$ \\
Norte & 981 & 4,12 & 17.605 & 3,20 & 6.566 & 5,18 & $1 / 365$ \\
Nordeste & 6.718 & 28,23 & 110.951 & 20,17 & 36.867 & 29,67 & $1 / 332$ \\
Sudeste & 10.365 & 43,55 & 305.482 & 55,39 & 55.294 & 43,61 & $1 / 181$ \\
Sul & 4.294 & 18,04 & 83.423 & 15,17 & 19.797 & 15,61 & $1 / 239$ \\
Centro Oeste & 1.443 & 6,06 & 32.570 & 5,92 & 8.282 & 6,53 & $1 / 251$ \\
\hline
\end{tabular}

FONTE: AMS - IBGE/ENSP - Pesquisa "Dinamica do Emprego em Saude no Brasil, 76/84".

* Exclui as categorias näo discriminads e classificadas como "outros", os empregos administrativos e serviços gerais. 
A região nordeste, por exemplo, detinha $29,07 \%$ da população brasileira e apenas $20 \%$ dos empregos "típicos" de saúde, e era na região norte onde se verificava a mais baixa relação empregos de profissionais de saúde/habitantes. (1 emprego para cada 365 habitantes, enquanto a média para o Brasil situava-se em mais emprego para cada 231 habitantes).

Relativamente em alguns estados para os quais dispomos de dados, verifica-se que é no Rio de Janeiro onde se encontra a maior concentração de empregos de profissionais de saúde por habitantes.

Neste estado a relação empregos típicos de saúde/habitantes era de 1 para 125, em seguida apareciam os estados de São Paulo e Rio Grande do Sul, com 1 para 180 e 1 para 198 empregos por habitantes, respectivamente.

Nos demais estados, inclusive Minas Gerais e Bahia, esta relação apresentava índices inferiores à média verificada para o Brasil.

A Tabela 8 mostra a distribuição regional dos empregos segundo a natureza (pública ou privada) dos estabelecimentos.

Sua análise evidencia que nas regiōes Sul e Sudeste prevalecem os estabelecimentos de natureza privada na absorção dos postos de trabalho típicos de saúde, ao passo que nas demais regiōes brasileiras predominam os estabelecimentos de natureza pública.

Assim, na região sul, perto e $60 \%$ dos postos de trabalho "típicos" de saúde vinculavam-se a estabelecimentos mantidos por instituição de natureza privada.

TABELA 8

DISTRIBUIÇÃO PERCENTUAL DOS POSTOS

DE TRABALHO* NOS ESTABELECIMENTOS

DE SAÚDE POR MACRORREGIŌES FISIOGRÁFICAS

BRASILEIRAS SEGUNDO A NATUREZA

DA ENTIDADE MANTENEDORA BRASIL, 1982

\begin{tabular}{lcc}
\hline \multirow{2}{*}{ REGIÕES } & \multicolumn{2}{c}{ NATUREZA DO ESTABELECIMENTO } \\
\cline { 2 - 3 } & PÚBLICO & PRIVADO \\
\hline Brasil & $51,32 \%$ & $46,68 \%$ \\
Norte & $67,57 \%$ & $32,43 \%$ \\
Nordete & $66,88 \%$ & $33,12 \%$ \\
Sudeste & $46,77 \%$ & $53,23 \%$ \\
Sul & $41,41 \%$ & $58,59 \%$ \\
Centro Oeste & $57,64 \%$ & $42,36 \%$ \\
\hline
\end{tabular}

Fonte: $A M S / I B G E$ - Pesquisa "Dinâmica do Emprego em Saúde no Brasil, 76/84", ENSP/UFMG. tros".

* Exclui postos de trabalho administrativos, serviços gerais $e$ "ou- 
Por outro lado, na região norte aproximadamente $68 \%$ destes "empregos" eram demandados pelo setor público.

Analisando os dados relativos aos estados (Tabela 9) podese verificar que é no estado de São Paulo onde os estabelecimentos privados comparecem com maior peso, no que respeita à absorção de postos de trabalho "típicos" de saúde (62,54\%). Neste estado, os estabelecimentos privados lucrativos considerados isoladamente, detinham perto de $32 \%$ do total de "empregos" de profissionais de saúde.*

No Rio Grande do Sul $60,60 \%$ dos postos de trabalho "tipicos" de saúde se localizavam em estabelecimentos privados, sendo que os de natureza filantropica e os beneficentes agregavam $38 \%$ do total de "empregos" de saúde do estado.

É interessante notar, quanto a este último estado, o extraordinário peso com que comparecem os estabelecimentos de saúde conveniados com o INAMPS na absorção dos postos de trabalho "típicos" de saúde. Estes detinham $81,77 \%$ dos "empregos", enquanto em São Paulo estes números não chegavam a $54 \%$.

Tamberm em Minas Gerais, os estabelecimentos privados se responsabilizavam pela maioria absoluta dos postos de trabalho $(57,74 \%)$.

Aqui, eram os estabelecimentos médico-sanitários de natureza jurfdica filantrópica e os beneficentes que respondiam pela maior parte dos "empregos" $(31,01 \%)$.

TABELA 9

DISTRIBUIÇÃO PERCENTUAL DOS POSTOS

DE TRABALHO* NOS ESTABELECIMENTOS

DE SAÚDE POR ALGUNS ESTADOS BRASILEIROS, SEGUNDO A NATUREZA

DA ENTIDADE MANTENEDORA BRASIL, 1982

\begin{tabular}{lcc}
\hline \multirow{2}{*}{ ESTADOS } & \multicolumn{2}{c}{ NATUREZA DO ESTABELECIMENTO } \\
\cline { 2 - 3 } & PÚBLICO & PRIVADO \\
\hline Brasil & $51,32 \%$ & $46,68 \%$ \\
Pernambuco & $70,30 \%$ & $29,70 \%$ \\
Bahia & $57,93 \%$ & $42,07 \%$ \\
Minas Gerais & $42,26 \%$ & $57,74 \%$ \\
Rio de Janeiro & $63,04 \%$ & $36,96 \%$ \\
São Paulo & $37,46 \%$ & $62,54 \%$ \\
Rio Grande & $39,40 \%$ & 60,60 \\
\hline do Sul & & \\
\hline
\end{tabular}

Fonte: $A M S / I B G E$ tros".

* Exclui postos de trabalho administrativos, serviços gerais e "ou-

* Dados da Pesquisa "Dinâmica do Emprego em Saúde. ." ja citada-Fonte: IBGE/AMS. 
Os "empregos" em estabelecimentos conveniados com o INAMPS somavam em 1982, 71,76\% dos "empregos" existentes neste estado.

O Rio de Janeiro, no que diz respeito à distribuição institucional dos postos de trabalho "típicos" de saúde, constitui excessão em relação aos demais estados do Sudeste e do Sul. Neste estado, onde por razões históricas, o serviço público é mais desenvolvido, especialmente os públicos federais, observou-se que $63,04 \%$ dos postos de trabalho "típicos" de saúde situavam-se em estabelecimentos mantidos por entidades ou instituições desta natureza.

É neste estado também onde os empregos vinculados a estabelecimentos que mantinham convênio com o INAMPS, apresentaram o menor peso relativo $(47,95 \%)$ comparativamente aos demais estados da federação (Tabela 10).

TABELA 10

POSTOS DE TRABALHO* E ESTABELCIMENTOS DE SAÚDE POR ALGUNS ESTADOS BRASILEIROS, SEGUNDO CONDIÇÃO DE CONVÊNIO COM O INAMPS BRASIL, $1976 / 1982$

\begin{tabular}{|c|c|c|c|c|c|c|c|c|}
\hline \multirow{3}{*}{ ESTADOS } & \multicolumn{4}{|c|}{ ESTABELECIMENTOS } & \multicolumn{4}{|c|}{ EMPREGOS } \\
\hline & \multicolumn{2}{|c|}{ TOTAIS } & \multicolumn{2}{|c|}{$\begin{array}{l}\text { CONVENIADOS } \\
\text { COM INAMPS }\end{array}$} & \multicolumn{2}{|c|}{ TOTAIS } & \multicolumn{2}{|c|}{$\begin{array}{l}\text { CONVENIADOS } \\
\text { COMINAMPS }\end{array}$} \\
\hline & ABSOLUTO & RELATIVO & ABSOLUTO & RELATIVO & ABSOLUTO & RELATIVO & ABSOLUTO & RELATIVO \\
\hline Brasil & 23.801 & 100,00 & 10.072 & 42,32 & 550.031 & 100,00 & 326.748 & 59,41 \\
\hline Pernambuco & 851 & 3,58 & 335 & 39,37 & 20.473 & 3,72 & 11.954 & 58,39 \\
\hline Bahia & 2.054 & 8,63 & 651 & 31,69 & 31.055 & 5,65 & 18.176 & 58,53 \\
\hline Minas Gerais & 3.227 & 13,56 & 1.759 & 54,51 & 49.731 & 9,04 & 35.688 & 71,76 \\
\hline Rio de Janeiro & 1.694 & 7,12 & 667 & 39,37 & 96.127 & 17,48 & 46.093 & 47,95 \\
\hline São Paulo & 4.948 & 20,79 & 1.302 & 26,31 & 151.115 & 27,47 & 80.531 & 53,29 \\
\hline \multirow{2}{*}{$\begin{array}{l}\text { Rio Grande } \\
\text { do Sul }\end{array}$} & & & & & & & & \\
\hline & 1.571 & 6,60 & 1.230 & 78,29 & 41.125 & 7,48 & 33.626 & 81,77 \\
\hline
\end{tabular}

Fonte: AMS/IBGE/ENSP - Pesquisa "Dinâmica do Emprego em Saúde no Brasil, 76/84".

* Excluı as categorlas nāo discrimınadas e classıficadas como "outros", os empregos admımıstratıvos e serviços geraus.

O Estado de Pernambuco, dentre aqueles para as quais dispomos de dados, foi onde o setor público compareceu com maior representatividade no que respeita à absorção dos postos de trabalho "típicos" de saúde. Aqui, 70,30\% destes "empregos" situavam-se em estabelecimentos mantidos por instituições de natureza pública.

Analisando finalmente a distribuição dos "empregos" de saúde por áreas de lotação da ocupação, os dados de 1983, indicam que a maioria absoluta dos postos de trabalho se encontrava lotada no atendimento Direto $(57,07 \%)$, como demonstra a Tabela 11.

Considerando-se os estados mais "desenvolvidos" no país, verifica-se que este percentual não variou muito de estado

Cadernos de Saúde Pública, R.J., 2 (4): 423-439, out/dez, 1986 
para estado (57,29\% em São Paulo, 55,45\% no Rio de Janeiro, $56,88 \%$ em Minas Gerais, 55,67\% no Rio Grande do Sul, 59,54\% na Bahia, 58,41\% no Pará e 59,47\% em Goiás).

As atividade de apoio ao diagnóstico e apoio terapêutico agregavam 7,02\% dos postos de trabalho enquanto as atividades administrativas e de serviços gerais somavam $35,91 \%$ do total dos postos de trabalho existentes nos estabelecimentos médico-sanitários em 1983.

TABELA 11

DISTRIBUIÇÃO DOS POSTOS DE TRABALHO* ESTABELECIMENTOS DE SAÚDE, SEGUNDO ÁREA DE LOTAÇÃO DO EMPREGO BRASIL, 1983

\begin{tabular}{lcc}
\hline \multicolumn{1}{c}{ ÁREA } & \multicolumn{2}{c}{ № DE POSTOS } \\
DE LOTAÇĀO & \multicolumn{2}{c}{ DE TRABALHO } \\
DO EMPREGO & ABSOLUTO & RELATIVO \\
\hline \multicolumn{1}{c}{ Administração } & 120.749 & 13,67 \\
Atendimento Direto & 504.308 & 57,07 \\
Apoio ao Diagnóstico & & \\
$\quad$ e Terapêutico & 62.001 & 7,02 \\
Serviços Gerais & 196.537 & 22,24 \\
TOTAL & 883.595 & 100,00 \\
\hline
\end{tabular}

FONTE: IBGE/AMS - Diretoria de Pop. e Social Anvario Estatistico, 1985.

" Inclui as categorias näo discriminadas e classificadas como "outros", os empregos adminstrativos e serviços gerais.

\section{CONCLUSÕES}

O fato de não termos, à data da conclusão deste artigo, os dados atualizados, relativos a 1984 e anos subseqüentes, impediu-nos de intentar quaisquer considerações mais definitivas acerca das tendências mais recentes de evolução dos postos de trabalho em saúde no Brasil.

A verificação da dinâmica do emprego entre 80 e 82 ह insuficiente, dado o pequeno lapso de tempo, para uma inferência segura sobre quaisquer movimentos mais sutis que porventura estejam se processando na realidade.

Dessa forma, nosso esforço de análise e interpretação, está sujeito a corroborações que certamente advirão no transcorrer de nossas investigações.

De qualquer maneira, pareceu-nos necessário ressaltar alguns dos movimentos, que na nossa apreciação se constituíram os mais significativos.

O primeiro deles é o que aponta para o aumento da participação do setor público na absorção dos postos de trabalho "típicos" de saúde, a nível dos estabelecimentos médico-sanitários. 
Verifica-se inclusive que os estabelecimentos mantidos por instituições desta natureza, especialmente os de nivel estadual, apresentaram, quer seja no segmento sem internação quer seja no segmento com internação, maiores ritmos de absorção de postos de trabalho a partir dos anos 80 , comparativamente ao período $76 / 80$.

De maneira inversa, os estabelecimentos de natureza privada, e muito particularmente, os não-lucrativos experimentaram a partir de 1980, menores ritmos de crescimento, comparativamente ao período 76/80. Exceção seja feita ao segmento privado lucrativo sem internação, que apresentaram tendências semelhantes à observada para o setor público.

Em segundo lugar verificou-se também um movimento de "ambulatorização" dos empregos "típicos" de saúde, com destaque para os estabelecimentos páblicos estaduais e municipais e privados lucrativos. Neste segmento verificou-se uma expressiva perda, em termos absolutos, de postos de trabalho "túpicos" de saúde, nos estabelecimentos privados não-lucrativos.

No que diz respeito à composição qualitativa e quantitativa do "emprego" em saúde, verificou-se que até 1980 não se observara nenhum movimento evidente no sentido da alteração do predomínio absoluto das categorias de ocupações de nivel universitário e elementar no setor, a partir de então começa a se detectar um vigoroso impulso nas taxas de crescimento e aumento gradativo da participação dos postos de trabalho de nível médio, que todavia, ainda em 1982, permaneciam em posição minoritária, representando apenas $22,05 \%$ do total de "empregos" existentes nos estabelecimentos. Em contrapartida o "empregos" de nível elementar experimentaram acentuada diminuição no seu crescimento e participação

Os postos de trabalho de atendentes, inclusive, vêm apresentando, a partir de 1981, incremento negativo a nível dos estabelecimentos privados com internação (lucrativos ou não) e nos privados sem internação formalmente não-lucrativos.

Pode ser que este fato seja expressão de possíveis mudanças nas políticas de absorção de força de trabalho de parte destes estabelecimentos.

Finalmente, quanto a distribuição regional dos postos de trabalho de saúde, verificou-se que estes ainda se concentram nas regiōes e estados mais desenvolvidos do país, onde concomitantemente, verifica-se com maior intensidade, a penetração de relaçōes capitalistas na prestação de serviços de saúde. Inclusive, foi nessas mesmas regiōes e estados, onde se verificou uma maior participação do setor privado na absorção dos postos de trabalho "típicos" de saúde.

1. ANUÁRIO ESTATISTICO DO BRASIL. Rio de Janeiro, FIBGE, 1985. 
2. LANGONI, C. G. Economia da transformação. Rio de Janeiro, Biblioteca do Exército, 1976. p. 154.

3. MEDICI, A.C. Estrutura e dinâmica da força de trabalho médica no Brasil na decada d 70. s.1. 1984. mimeo.

4. MEDICI, A.C. A força de trabalho em saúde no Brasil dos anos 70: percalços e tendências. Rio de Janeiro, 1984. mimeo

5. NOGUEIRA, R.P. A dinâmica do mercado de trabalho em saúde no Brasil.Brasília, OPS, 1986.

6. SINGER, P. Economia politica do trabalho: elementos para uma análise histórico-estrutural do emprego e da força de trabalho no desenvolvimento capitalista. São Paulo, HUCITEC, 1977. p. 5; 63-73.

7. SPINDEL, R. C.Homens e máquinas na transição de uma economia cafeeira: formação e uso da força de trabalhos. Rio de Janeiro, Paz e Terra, 1979. 